\title{
Adrenal suppression in bronchiectasis and the impact of inhaled corticosteroids
}

\author{
J. Holme*,\#, J.W. Tomlinson" ${ }^{\#}$ R.A. Stockley*,\#, P.M. Stewart*,", \\ N. Barlow" and A.L. Sullivan*
}

ABSTRACT: The present study identified three patients with bronchiectasis receiving inhaled corticosteroids (ICSs) who had symptomatic adrenal suppression secondary to ICS. The prevalence of adrenal suppression is unknown in bronchiectasis. The frequency of adrenal suppression and the impact of ICS use in bronchiectasis patients were examined.

In total, 50 outpatients (33 receiving ICSs) underwent a short Synacthen test and completed a St George's Respiratory Questionnaire (SGRQ). Symptoms of adrenal suppression, steroid use and lung function were compared between subjects who were suppressed and those who were not.

Adrenal suppression was evident in $\mathbf{2 3 . 5 \%}$ of subjects who did not receive ICSs and $48.5 \%$ of those who did. Basal cortisol and the increments by which cortisol increased $\mathbf{3 0}$ min after Synacthen were lower in suppressed than in nonsuppressed subjects. The incremental cortisol rise was negatively correlated with SGRQ impacts and total score, suggesting a worse quality of life in those who had an impaired adrenal response. The greatest frequency of generalised symptoms was seen in the suppressed group.

A significant proportion of subjects with bronchiectasis have evidence of adrenal suppression, and this is increased when inhaled corticosteroids are also used. Impairment of the cortisol response to stimulation is associated with poorer health status.

KEYWORDS: Adrenal insufficiency, bronchiectasism, glucocorticoids, inhaled corticosteroid, short synacthen test

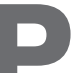
atients with bronchiectasis often describe nonspecific symptoms, including tiredness and lack of energy, which are usually attributed to their underlying inflammatory disease. These symptoms become worse during an exacerbation and are believed to relate to an increased inflammatory burden, such as that in chronic obstructive pulmonary disease (COPD) [1].

However, the current authors have identified three patients with bronchiectasis taking long-term inhaled corticosteroids (ICSs) who presented with generalised symptoms (lethargy, malaise, depression, arthralgia, nausea, vomiting, weight loss, falls, light-headedness and postural hypotension) that became worse during periods labelled as exacerbations of lung disease. Following investigation, they were found to have adrenal suppression (table 1). Unfortunately, adrenocorticotropic hormone $(\mathrm{ACTH})$ was only measured in one patient and was found to be undetectable. In all cases, there was no history of excessive or recent oral steroid use and no other reasons for adrenal insufficiency were identified, thus ICSs were considered to be the cause. The symptoms and short Synacthen test (SST) continued to improve for 2 yrs after commencing hydrocortisone replacement and changing inhaled fluticasone to ciclesonide, but was not yet within the normal range in one case (basal cortisol in abnormal case: $181 \mathrm{nmol} \cdot \mathrm{L}^{-1}$; post-stimulation cor-

Several studies have demonstrated that ICS treatment is associated with a rapid dose-dependent fall in serum cortisol, implying that systemic absorption occurs, leading to suppression of the hypothalamo-pituitary-adrenal (HPA) axis [2]. Subsequently, safety studies, many of which were generated by the pharmaceutical industry, have generally used static measures of serum cortisol, which show small reductions in circulating cortisol that are considered to be clinically insignificant [3]. Importantly, these studies are in large cohorts and individual patients show great variability in response; therefore, a small average fall in serum cortisol in subjects treated with ICSs does not exclude a large fall in some patients. Another common misconception is that cortisol secretion must be greatly suppressed before the adrenal glands become resistant to stimulation. In reality there is a poor relationship between basal levels of tisol: $\left.344 \mathrm{nmol} \cdot \mathrm{L}^{-1}\right)$.
AFFILIATIONS

*Lung Investigation Unit,

-Dept of Biochemistry, University

Hospital Birmingham NHS

Foundation Trust, and

"Dept of Endocrinology, Division of

Medical Sciences, University of

Birmingham, Birmingham, UK.

CORRESPONDENCE

R.A. Stockley

Lung Investigation Unit

1st Floor Nuffield House

Queen Elizabeth Hospital

Birmingham

B1 1TW

UK

Fax: 441216978257

E-mail: rob.stockley@uhb.nhs.uk

Received:

February 042008

Accepted after revision:

May 092008

\section{STATEMENT OF INTEREST}

Statements of interest

for R.A. Stockley, P.M. Stewart and

A.L. Sullivan, and for the study itself

can be found at www.erj.ersjournals.

com/misc/statements.shtml 


\begin{tabular}{|c|c|c|c|c|c|c|c|c|}
\hline \multicolumn{2}{|c|}{ TABLE 1} & \multicolumn{7}{|c|}{$\begin{array}{l}\text { Clinical features of three patients with chronic lung disease with adrenal suppression attributed to prolonged inhaled } \\
\text { orticosteroid therapy }\end{array}$} \\
\hline Case & Sex & Age yrs & Diagnosis & $\begin{array}{c}\text { Daily } \\
\text { maintenance } \\
\text { treatment }\end{array}$ & $\begin{array}{c}\text { Extra steroid } \\
\text { treatment }\end{array}$ & Symptoms and signs & $\begin{array}{c}\text { Basal } \\
\text { cortisol } \\
\mathrm{nmol} \cdot \mathrm{L}^{-1}\end{array}$ & $\begin{array}{l}\text { Post- } \\
\text { Synacthen } \\
\text { cortisol } \\
\text { nmol } \cdot \mathrm{L}^{-1}\end{array}$ \\
\hline 1 & Female & 27 & $\begin{array}{c}\text { Bronchiectasis } \\
\text { Asthma }\end{array}$ & $1 \mathrm{mg}$ fluticasone & $\begin{array}{l}2-3 \text { short } \\
\text { courses oral } \\
\text { prednisolone } \\
\text { per yr }\end{array}$ & $\begin{array}{l}\text { Fatigue, lethargy, } \\
\text { malaise, depression, } \\
\text { nausea, vomiting, } \\
\text { hypotension especially with } \\
\text { exacerbation }\end{array}$ & $<20$ & 32 \\
\hline 2 & Female & 63 & $\begin{array}{c}\text { COPD } \\
\text { Bronchiectasis }\end{array}$ & $1 \mathrm{mg}$ fluticasone & $\begin{array}{l}2 \text { short courses } \\
\text { prednisolone } \\
\text { per yr } \\
\text { Occasional } \\
\text { nasal steroid }\end{array}$ & $\begin{array}{c}\text { Fatigue, falls, } \\
\text { postural } \\
\text { hypotension }\end{array}$ & 80 & 253 \\
\hline 3 & Female & 81 & Bronchiectasis & $1 \mathrm{mg}$ fluticasone & $\begin{array}{l}4-5 \text { short } \\
\text { courses } \\
\text { prednisolone } \\
\text { per yr }\end{array}$ & $\begin{array}{c}\text { Arthralgia, malaise, } \\
\text { fatigue }\end{array}$ & 175 & 397 \\
\hline
\end{tabular}

COPD: chronic obstructive pulmonary disease.

cortisol and the increase in cortisol secretion during intercurrent illness [4]. Clearly, in an illness such as bronchiectasis, which is characterised by recurrent episodes of acute infection, the ability of the HPA axis to respond appropriately to stress is fundamentally important. Therefore, the use of a dynamic test of adrenal function, such as the SST, is warranted.

Stimulatory studies have been performed in order to examine the ability of the adrenal gland to respond to stress, but these have usually been restricted to patients treated with steroids for a short duration ( $<12$ weeks), or there have been confounding factors (including the concomitant use of cytochrome P450 inhibitors), thus the quoted risks of adrenal impairment may be misleading [5-9].

Therefore, it was hypothesised that adrenal suppression in subjects with bronchiectasis receiving ICSs may be more common than widely believed and may contribute to symptoms. In the current study, the HPA axis in a group of patients with bronchiectasis was studied and its relationship with the severity and impact of their respiratory disease was examined.

\section{METHODS}

Sequential patients who attended a tertiary referral bronchiectasis clinic, were eligible for the study and willing to give informed consent were included, up to a total of 50 patients. In total, 33 were on regular ICSs (for $>1 \mathrm{yr}$ ) whilst the remaining 17 had not received ICSs over the previous year. Patients who had taken more than three courses of oral steroids over the previous year, received oral steroid over the previous 6 weeks and those on long-term nebulised steroids were excluded from the study. All subjects attended following an overnight fast, having discontinued inhaled steroids $24 \mathrm{~h}$ previously. Blood was taken at 08:00 h for basal cortisol, ACTH and glucose.
Synthetic $\mathrm{ACTH}_{1-24} 250 \mu \mathrm{g}$ (Alliance Pharma Plc, Chippenham, UK) was administered intramuscularly and blood was taken $30 \mathrm{~min}$ later for cortisol. Subjects completed a St George's Respiratory Questionnaire (SGRQ) and blood pressure was measured while supine, and at 1 and $3 \mathrm{~min}$ after standing.

\begin{tabular}{|c|c|c|c|c|}
\hline \multirow[t]{2}{*}{ TABLE 2} & \multicolumn{4}{|c|}{$\begin{array}{l}\text { Demographic data and short Synacthen test } \\
\text { (SST) results for study subjects divided } \\
\text { according to the use of inhaled corticosteroids } \\
\text { (ICSs) }\end{array}$} \\
\hline & & No ICS & ICS & p-value \\
\hline \multicolumn{2}{|l|}{ Subjects $\mathrm{n}$} & 17 & 33 & \\
\hline \multicolumn{2}{|l|}{ Females } & $14(82.4)$ & $22(66.7)$ & 0.33 \\
\hline \multicolumn{2}{|l|}{ Males } & $3(17.6)$ & $11(33.3)$ & \\
\hline \multicolumn{2}{|l|}{ Age yrs } & $62 \pm 2$ & $64 \pm 2$ & 0.66 \\
\hline \multicolumn{2}{|l|}{ FEV $1 \%$ pred } & $56.2 \pm 4.9$ & $54.3 \pm 3.5$ & 0.76 \\
\hline \multicolumn{2}{|l|}{ FEV $_{1 / \text { FVC }}$} & $61.7 \pm 2.3$ & $56.5 \pm 2.8$ & 0.15 \\
\hline \multicolumn{2}{|l|}{ Kco \% pred } & $105.4 \pm 6.2$ & $103.4 \pm 5.2$ & 0.90 \\
\hline \multicolumn{2}{|c|}{$\begin{array}{l}\text { Taken oral steroid in previous } \\
3 \text { months }\end{array}$} & $1(6)$ & $5(15)$ & 0.65 \\
\hline \multicolumn{2}{|c|}{ Basal cortisol nmol. $\mathrm{L}^{-1}$} & $412 \pm 26$ & $400 \pm 20$ & 0.71 \\
\hline \multicolumn{2}{|c|}{$\begin{array}{l}\text { Cortisol post-Synacthen } \\
\mathrm{nmol} \cdot \mathrm{L}^{-1}\end{array}$} & $609 \pm 27$ & $565 \pm 20$ & 0.20 \\
\hline \multicolumn{2}{|c|}{ ACTH $n g \cdot \mathrm{L}^{-1}$} & $24.3 \pm 2.8$ & $31.5 \pm 3.6$ & 0.12 \\
\hline \multicolumn{2}{|c|}{ Cortisol increment $\mathrm{nmol} \cdot \mathrm{L}^{-1}$} & $197 \pm 24$ & $165 \pm 17$ & 0.29 \\
\hline \multicolumn{2}{|c|}{ SST test failures } & $4(23.5)$ & $16(48.5)$ & 0.04 \\
\hline
\end{tabular}

Data are presented as $n(\%)$ or mean \pm SEM, unless otherwise stated. FEV1: forced expiratory volume in one second; \% pred: \% predicted; FVC: forced vital capacity; KCO: transfer coefficient of the lung for carbon monoxide; ACTH: adrenocorticotropic hormone. 

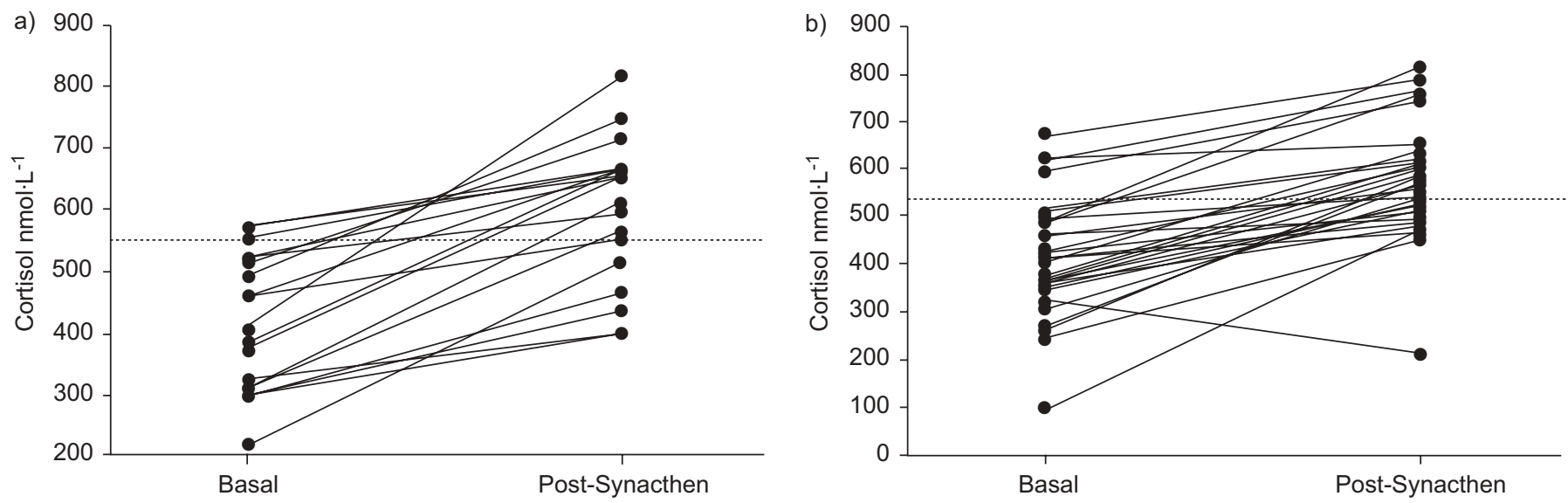

FIGURE 1. Basal and 30 min post-stimulation serum cortisol levels ( $n$ mol $\cdot \mathrm{L}^{-1}$ ) for subjects who a) did not receive inhaled corticosteroid and b) did receive regular inhaled corticosteroid. …....... abnormal 30 min cortisol values.

Postural hypotension was defined as a fall in systolic blood pressure of $>20 \mathrm{mmHg}$ and a fall in diastolic blood pressure of $>10 \mathrm{mmHg}$ upon standing [10]. Forced expiratory volume in one second (FEV1), forced vital capacity (FVC) and transfer factor corrected for alveolar volume (KCO) were assessed using Vitalograph Wedge Bellows (Vitalograph, Maids Moreton, UK) and Benchmark TT501 (Morgan Medical, Gillingham, UK), and expressed as \% predicted [11].

Serum cortisol was analysed using a chemiluminescent immunoassay (Advia Centaur; Siemans Medical Solutions, Newbury, UK). Plasma ACTH was analysed by a chemiluminometric assay (Immulite 2000; Siemans Medical Solutions, Llanberis, UK); and glucose was analysed using a ROCHE Modular (ROCHE Diagnostics, Indianapolis, IN, USA). Adrenal insufficiency was defined as a cortisol concentration $<550 \mathrm{nmol} \cdot \mathrm{L}^{-1} 30 \mathrm{~min}$ after Synacthen administration, as previously reported [12].

For tests of significant differences, the Chi-squared test was performed for categorical data, the unpaired t-test was used for normally distributed continuous variables and the MannWhitney test was used for nonparametric continuous data. Pearson's correlations were used to compare two continuous parametric variables, and Spearman's correlations were used for nonparametric variables. Data are presented as mean $\pm S E M$, unless otherwise stated, and $\mathrm{p}<0.05$ was regarded as significant.

The study was approved by the South Birmingham Research Ethics Committee (Birmingham, UK).

\section{RESULTS}

In total, 50 patients with bronchiectasis were enrolled. There was no significant difference in sex, age, FEV1\% pred, FEV1/ FVC ratio, KCO \% pred, the number of patients with bronchodilator reversibility $(>200 \mathrm{~mL}$ and $12 \%$ pred value [13]) or the number who had taken oral steroids over the previous 3 months, between those who received ICSs and those who did not (table 2).

In total, $48.5 \%$ (16 out of 33 ) of patients on ICSs and $23.5 \%$ (four out of 17) of the subjects who did not receive ICSs had evidence of adrenal impairment $(\mathrm{p}=0.043$ for ICS versus no ICS; fig. 1).

Basal cortisol levels were significantly lower in subjects with adrenal suppression compared with those who responded adequately (mean \pm SEM $335 \pm 19$ versus $450 \pm 9 \mathrm{nmol} \cdot \mathrm{L}^{-1}$; $\mathrm{p}<0.001)$. In addition, the incremental cortisol response (30min cortisol minus basal cortisol) was lower in suppressed patients compared with those who were not suppressed $\left(141 \pm 23\right.$ versus $\left.199 \pm 90 \mathrm{nmol} \cdot \mathrm{L}^{-1} ; \mathrm{p}=0.05\right)$. No differences were observed between groups for ACTH or fasting serum glucose levels (table 3).

There were no differences in age, sex, lung function, ICS drug preparation and dose (corrected for bioequivalence), mouth rinsing after ICS, and spacer use, between those who were suppressed and those who were not. Furthermore, the number of courses and total dose of oral steroids over the preceding 3 months and $1 \mathrm{yr}$, the use of nasal and topical steroids and Coadministration of drugs known to inhibit cytochrome P450 3A4 were not different between those patients with adrenal suppression and those without (data not shown).

Although there were no significant differences between average health status in the suppressed and nonsuppressed group, the incremental cortisol response was related to respiratory health. Cortisol increment across the SST inversely correlated with the impact domain $(\mathrm{r}=-0.338, \mathrm{p}=0.016)$, and the total SGRQ score $(r=-0.328, p=0.020$; fig. 2$)$, suggesting that poor incremental cortisol response is associated with reduced quality of life. However, there was no correlation with the symptoms and activity variables of the SGRQ ( $r=0.020$, $\mathrm{p}=0.245$, and $\mathrm{r}=0.018, \mathrm{p}=0.110$, respectively).

Of the subjects receiving ICSs, a greater proportion of suppressed subjects described tiredness (100\%), nausea $(50 \%)$ and vomiting $(25 \%)$, compared with those with no suppression $(82.4 \%, 29.4 \%$ and $5.9 \%$, respectively). The proportion of suppressed patients with postural hypotension at $1 \mathrm{~min}$ $(50 \%), 3 \mathrm{~min}(75 \%)$ or at any time $(75 \%)$ was higher compared with nonsuppressed patients (30.8, 38.5 and 53.8\%, respectively). When analysed as a complete cohort, tiredness, 


\begin{tabular}{|c|c|c|c|c|}
\hline \multirow[t]{2}{*}{ TABLE 3} & \multicolumn{4}{|c|}{$\begin{array}{l}\text { Demographic data and short Synacthen test } \\
\text { results for study subjects divided according to } \\
\text { evidence of adrenal suppression }\end{array}$} \\
\hline & & $\begin{array}{c}\text { Not } \\
\text { suppressed }\end{array}$ & Suppressed & p-value \\
\hline \multicolumn{2}{|l|}{ Subjects $n$} & 30 & 20 & \\
\hline \multicolumn{2}{|l|}{ Males } & $9(64.3)$ & $5(35.7)$ & 0.70 \\
\hline \multicolumn{2}{|l|}{ Females } & $21(58.3)$ & $15(41.7)$ & \\
\hline \multicolumn{2}{|l|}{ Age yrs } & $62 \pm 2$ & $64 \pm 3$ & 0.661 \\
\hline \multicolumn{2}{|c|}{ Number receiving ICS } & 17 & 16 & 0.043 \\
\hline \multicolumn{2}{|c|}{ FEV1 \% pred } & $55.3 \pm 3.9$ & $56.9 \pm 4.7$ & 0.790 \\
\hline \multicolumn{2}{|l|}{$\mathrm{FEV}_{1 / \text { FVC }}$} & $58.1 \pm 2.5$ & $61.7 \pm 3.5$ & 0.407 \\
\hline \multicolumn{2}{|l|}{ Kco \% pred } & $103.8 \pm 4.0$ & $110.7 \pm 4.7$ & 0.272 \\
\hline \multicolumn{2}{|c|}{ Basal cortisol nmol $\cdot \mathrm{L}^{-1}$} & $450 \pm 9$ & $335 \pm 19$ & $<0.001$ \\
\hline \multicolumn{2}{|c|}{$\begin{array}{l}\text { Incremental cortisol } \\
\text { response } \mathrm{nmol} \cdot \mathrm{L}^{-1}\end{array}$} & $199 \pm 90$ & $141 \pm 23$ & 0.05 \\
\hline \multicolumn{2}{|l|}{ ACTH $n g \cdot L^{-1}$} & $28.5 \pm 3.4$ & $29.8 \pm 4.0$ & 0.804 \\
\hline \multicolumn{2}{|c|}{ Fasting glucose $\mathrm{mmol} \cdot \mathrm{L}^{-1}$} & $4.9 \pm 0.1$ & $5.1 \pm 0.4$ & 0.575 \\
\hline \multicolumn{2}{|c|}{ Systolic blood pressure $\mathrm{mmHg}$} & $145 \pm 4.2$ & $145 \pm 5.5$ & 1.0 \\
\hline \multicolumn{2}{|c|}{ Diastolic blood pressure $\mathrm{mmHg}$} & $83 \pm 2.3$ & $82 \pm 1.9$ & 0.807 \\
\hline \multicolumn{5}{|c|}{ Postural hypotension } \\
\hline \multicolumn{2}{|l|}{$1 \mathrm{~min}$} & $8(26.7)$ & 7 (35) & 0.53 \\
\hline \multicolumn{2}{|l|}{$3 \mathrm{~min}$} & $12(40)$ & $6(30)$ & 0.47 \\
\hline \multicolumn{2}{|l|}{ Anytime } & $14(46.7)$ & $9(45)$ & 0.91 \\
\hline \multicolumn{2}{|l|}{ Tiredness } & $27(90)$ & $20(100)$ & 0.27 \\
\hline \multicolumn{2}{|c|}{ Generalised weakness } & 19 (63.3) & $13(65)$ & 0.90 \\
\hline \multicolumn{2}{|c|}{ Lack of energy } & 25 (83.3) & $18(90)$ & 0.69 \\
\hline \multicolumn{2}{|l|}{ Weight loss } & $10(33.3)$ & $8(40)$ & 0.69 \\
\hline \multicolumn{2}{|l|}{ Nausea } & $9(30)$ & $10(50)$ & 0.15 \\
\hline \multicolumn{2}{|l|}{ Vomiting } & $2(6.6)$ & $5(25)$ & 0.42 \\
\hline \multicolumn{5}{|l|}{ SGRQ } \\
\hline \multicolumn{2}{|c|}{ Symptoms domain } & $47.6 \pm 1.9$ & $42.9 \pm 2.3$ & 0.125 \\
\hline \multicolumn{2}{|c|}{ Activity domain } & $66.8 \pm 3.5$ & $61.6 \pm 5.8$ & 0.450 \\
\hline \multicolumn{2}{|c|}{ Impact domain } & $35.5 \pm 3.0$ & $40.5 \pm 5.0$ & 0.404 \\
\hline \multicolumn{2}{|l|}{ Total } & $47.0 \pm 2.5$ & $47.3 \pm 4.4$ & 0.962 \\
\hline
\end{tabular}

Data are presented as $n(\%)$ or mean \pm SEM, unless otherwise stated. ICS: inhaled corticosteroid; FEV1: forced expiratory volume in one second; \% pred: $\%$ predicted; FVC: forced vital capacity; Kco: transfer coefficient of the lung for carbon monoxide; ACTH: adrenocorticotropic hormone; SGRQ: St George's Respiratory Questionnaire.

generalised weakness, lack of energy, weight loss, nausea and vomiting were all more common amongst individuals with suppression of the HPA axis (table 3). However, owing to the relatively small number of individuals within the present study, none of these observations reached statistical significance. There were no abnormalities of serum electrolytes (sodium or potassium) and no differences between those with evidence of suppression and those without.

\section{DISCUSSION}

The present data, from a cross-sectional study of patients with bronchiectasis, have clearly shown that the prevalence of adrenal suppression is two-fold higher in patients receiving ICSs compared with those who are not. Importantly, a poor incremental cortisol response to SST was associated with a poor respiratory quality of life as measured by SGRQ. With the
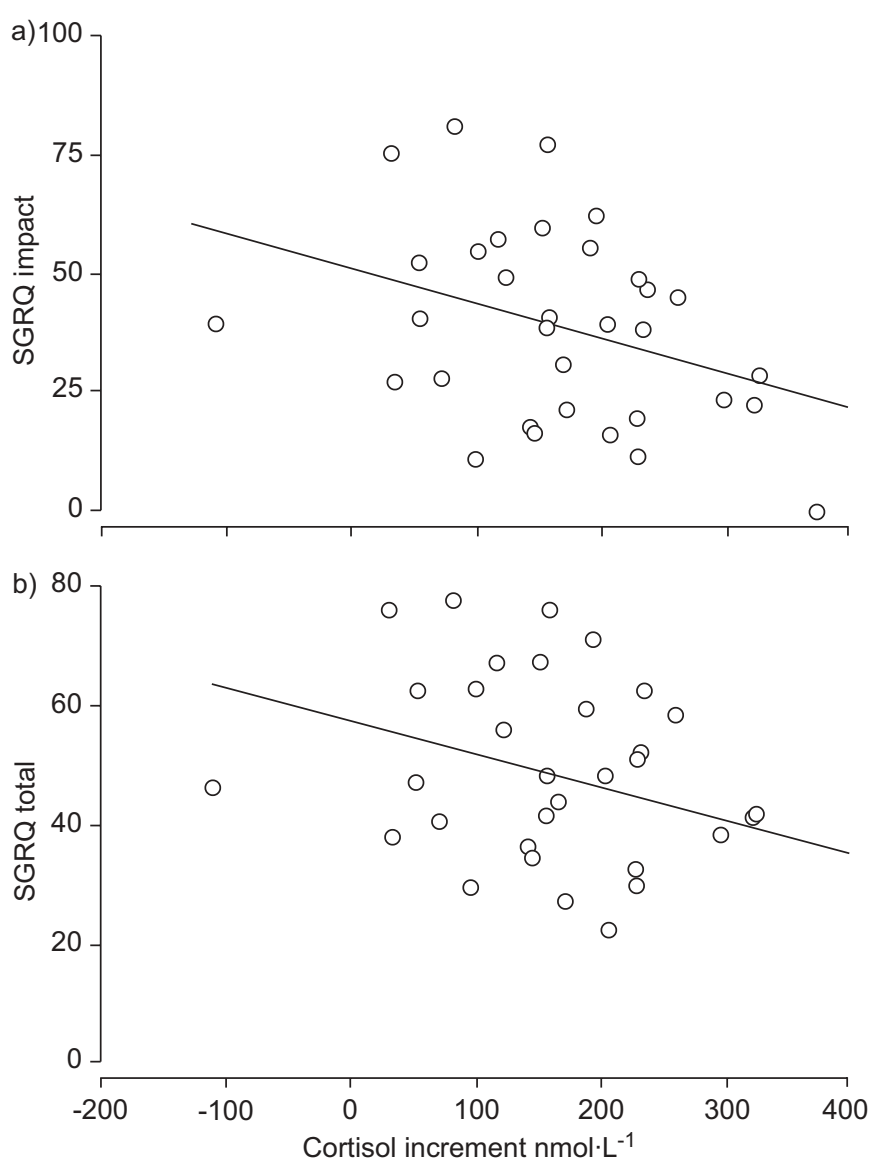

FIGURE 2. a) St George's Respiratory Questionnaire (SGRQ) impact domain score and b) SGRQ total score and the relationship to the cortisol increment following stimulation with synthetic adrenocorticotropic hormone. $\bigcirc$ : a single patient.

exception of the use of ICSs, no specific factors that were associated with adrenal insufficiency could be identified.

Several studies have examined the dynamic adrenal function in healthy subjects and patients with asthma or COPD who have received ICSs, and many have yielded negative results. However, there are important differences in the methodology and patient characteristics when compared with the present study. Healthy volunteers or patients with asthma taking ICSs for $<8$ weeks were previously found to have no abnormality in the SST [5-8]. In the present cohort, all patients had been on ICSs for $>1 \mathrm{yr}$. Studies in COPD patients from the Lung Health Study II also failed to demonstrate any abnormality using the SST after 3 yrs of ICS therapy [14]. However, these patients had mild disease and the inhaled triamcinolone was administered at a low dose. Although pre- and post-stimulation cortisol levels were lower in the group of patients on ICSs compared with the placebo group, they were not significantly different. As only mean values are given, it is possible that some individual patients did have adrenal insufficiency that was not reflected in the average value for the whole cohort. If the present data are analysed in a similar manner, there is no difference in the mean post-stimulation cortisol levels $(p=0.198)$ nor the cortisol increment $(p=0.288)$ between subjects who receive regular ICSs and those who do not. Therefore, this masks the important observation that a 
significantly greater proportion of subjects who receive ICSs have adrenal suppression. In agreement with the present results, one small study of 12 asthmatic patients with no confounding factors reported adrenal insufficiency in $25 \%$ of patients who had taken beclomethasone $\left(200-900 \mu \mathrm{g} \cdot\right.$ day $\left.^{-1}\right)$ for 12 weeks, suggesting that suppression may be more common than is currently believed [15].

The correlation of incremental cortisol response with SGRQ is an interesting observation and it is reasonable to speculate that at least some of the impact of their disease state in these patients may be attributed to "occult" adrenal insufficiency. Furthermore, the question arises as to whether, in some circumstances, hospital presentation may be related to adrenal insufficiency yet inappropriately labelled as an "exacerbation" of underlying lung disease due to nonspecific symptomatology. The administration of glucocorticoids in this setting will undoubtedly improve the clinical condition, but this does not assist in establishing the underlying diagnosis.

The use of the incremental cortisol response is not generally advocated in "routine" endocrine testing; however, in the context of chronic illness, or in the setting of intensive care [16], it would seem valid that the inability to mount an adequate cortisol response to stimulation may be an important marker of inadequate adrenal reserve. Studies in intensive care units suggest that functional adrenal impairment is present in $\sim 50 \%$ of patients and is associated with a marked increase in mortality [17-19]. In these subjects, a rapid HPA response to stress would be appropriate, and it is possible that traditionally "normal" values of serum cortisol are actually physiologically deficient when the metabolic needs of these patients are taken into account.

The role of ICSs in bronchiectasis remains unclear, owing to a lack of specific research studies, although there are suggestions that lung function may improve in some patients [20]. Approximately $20 \%$ of patients with bronchiectasis have clear bronchodilator reversibility with $\beta$-agonists [21] and $45 \%$ have bronchial hyperreactivity, as defined by the methacholine challenge [22], suggesting they may benefit from ISCs as part of their "asthma" management.

However, there are also theoretical reasons for caution in prescribing inhaled steroids to patients with bronchiectasis. Systemic absorption is more likely from airways with damaged epithelium, and impaired ciliary function and may lead to retention of the steroid in the airway, further exacerbating the problem. The possibility of increased systemic absorption because of damage in the airway may explain why a larger proportion of the present study patients have adrenal insufficiency while receiving ICSs. However, $24 \%$ of subjects who did not receive ICSs were also found to have adrenal insufficiency, so other possible explanations need to be considered. Patients with other inflammatory conditions, such as rheumatoid arthritis, have been shown to have reduced unstimulated levels of serum cortisol along with increased interleukin (IL)-1 $\beta$ and IL-6 compared with patients with noninflammatory osteoarthritis [23]. In these patients, a defect at the level of hypothalamic corticotrophin-releasing hormone $(\mathrm{CRH})$ production and release has been postulated, and this remains a possibility in the present cohort. In rodents, the proinflammatory cytokine, tumour necrosis factor (TNF)- $\alpha$, can inhibit CRH-stimulated ACTH release, although unstimulated levels of ACTH are unaffected [24]. In addition, production of cortisol by fetal adrenal cells is also inhibited by TNF- $\alpha$ in adults [25]. However, there was no difference in the circulating TNF- $\alpha$ levels in the present study patients with and without impaired SST response (data not shown). Lewis rats are a rodent model that is susceptible to inducible inflammatory conditions [26]. These rodents also display impaired CRH secretion and, as a consequence, impaired cortisol response.

A further possible explanation for the high proportion of adrenal suppression in subjects with bronchiectasis could be that patients with this chronic disease have lower levels of cortisol binding globulin, which results in lower total cortisol concentrations even though serum-free cortisol may remain consistent with a normal adrenal response. However, cortisol binding globulin in stored serum from this study was subsequently measured, and no difference was found in the levels when suppressed and nonsuppressed subjects were compared

The results of the present study have significant implications for the management of patients with bronchiectasis and may be generalised to other patients with chronic lung disease, including COPD and asthma. Given the low sensitivity of baseline cortisol in distinguishing between suppressed and nonsuppressed patients [27], the present authors would advocate the use of the SST to identify adrenal suppression in these patients. Owing to the lack of previous similar studies, the best clinical practice has not as yet been defined, yet there is an urgent clinical need bearing in mind the magnitude of the problem. Clearly there is a balance between preventing adrenal crisis and not contributing to total glucocorticoid load. In the present authors' practice, a combined respiratory and endocrinological approach has been pursued. Where possible, ICS doses have been reduced and, in some cases, ICS switched to ciclesonide (accepting that it is currently only licensed for asthma), which is only activated in lung cells [28], and is reported to cause less adrenal suppression. For patients with a $30 \mathrm{~min}$ cortisol $<400 \mathrm{nmol} \cdot \mathrm{L}^{-1}$, the present authors would advocate low-dose hydrocortisone replacement $\left(5-10 \mathrm{mg} \cdot\right.$ day $\left.^{-1}\right)$ with repeat SST after modification of ICS therapy in order to assess the return of HPA axis function. During intercurrent illness, increasing hydrocortisone replacement to $30 \mathrm{mg} \cdot \mathrm{day}^{-1}$ is recommended by the present authors. For patients with mild suppression ( $30 \mathrm{~min}$ cortisol $400-550 \mathrm{nmol} \cdot \mathrm{L}^{-1}$ ) the present authors would suggest hydrocortisone supplementation $\left(30 \mathrm{mg} \cdot \mathrm{day}^{-1}\right)$ only at the time of intercurrent illness.

In conclusion, a significant and important clinical problem has been uncovered. Assessment of adrenal function by a dynamic test is safe and simple, and may identify adrenal insufficiency that could account for many of the symptoms currently attributed to chronic lung disease. Larger studies are now urgently needed to determine whether adrenal insufficiency contributes to morbidity and, potentially, to mortality, not only in patients with bronchiectasis but all patients on inhaled corticosteroids.

\section{ACKNOWLEDGEMENTS}

The authors would like to thank P. Clark (Dept of Biochemistry, University Hospital Birmingham NHS Foundation Trust, Birmingham, UK) for technical advice, and D. Griffiths and 
T. Devaney from the Lung Investigation Unit (University Hospital Birmingham) for clinical and administrative support.

\section{REFERENCES}

1 Gompertz S, O’Brien C, Bayley DL, Hill SL, Stockley RA. Changes in bronchial inflammation during acute exacerbations of chronic bronchitis. Eur Respir J 2001; 17: 1112-1119.

2 Donnelly R, Williams KM, Baker AB, Badcock CA, Day RO, Seale JP. Effects of budesonide and fluticasone on 24-hour plasma cortisol. A dose-response study. Am J Respir Crit Care Med 1997; 156: 1746-1751.

3 British guideline on the management of asthma. Thorax 2003; 58: Suppl. 1, i1-i94.

4 Brown PH, Blundell G, Greening AP, Crompton GK. Screening for hypothalamo-pituitary-adrenal axis suppression in asthmatics taking high dose inhaled corticosteroids. Respir Med 1991; 85: 511-516.

5 Chervinsky P, van As A, Bronsky EA, et al. Fluticasone propionate aerosol for the treatment of adults with mild to moderate asthma. The Fluticasone Propionate Asthma Study Group. J Allergy Clin Immunol 1994; 94: 676-683.

6 Dahl R, Lundback B, Malo JL, et al. A dose-ranging study of fluticasone propionate in adult patients with moderate asthma. International Study Group. Chest 1993; 104: 1352-1358.

7 Wilson AM, McFarlane LC, Lipworth BJ. Effects of low and high doses of inhaled flunisolide and triamcinolone acetonide on basal and dynamic measures of adrenocortical activity in healthy volunteers. J Clin Endocrinol Metab 1998; 83: 922-925.

8 Szefler S, Rohatagi S, Williams J, Lloyd M, Kundu S, Banerji D. Ciclesonide, a novel inhaled steroid, does not affect hypothalamic-pituitary-adrenal axis function in patients with moderate-to-severe persistent asthma. Chest 2005; 128: 1104-1114.

9 Rouanet I, Peyriere H, Mauboussin JM, Vincent D. Cushing's syndrome in a patient treated by ritonavir/ lopinavir and inhaled fluticasone. HIV Med 2003; 4: 149-150.

10 Lahrmann H, Cortelli P, Hilz M, Mathias CJ, Struhal W, Tassinari M. EFNS guidelines on the diagnosis and management of orthostatic hypotension. Eur J Neurol 2006; 13: 930-936.

11 Quanjer PH, Tammeling GJ, Cotes JE, et al. Symbols, abbreviations and units. Working Party Standardisation of Lung Function Tests, European Community for Steel and Coal. Eur Respir J 1993; 6: Suppl. 16, 85-100.

12 Stewart PM, Clark PM, Sheppard MC. Comparison of the short ACTH stimulation test with the insulin tolerance/ glucagon test. Clin Endocrinol (Oxf) 1998; 48: 124-126.

13 Pellegrino R, Viegi G, Brusasco V, et al. Interpretative strategies for lung function tests. Eur Respir J 2005; 26: 948-968.
14 Eichenhorn MS, Wise RA, Madhok TC, et al. Lack of longterm adverse adrenal effects from inhaled triamcinolone: Lung Health Study II. Chest 2003; 124: 57-62.

15 Niitsuma T, Okita M, Sakurai K, et al. Adrenal function as assessed by low-dose adrenocorticotropin hormone test before and after switching from inhaled beclomethasone dipropionate to inhaled fluticasone propionate. J Asthma 2003; 40: 515-522.

16 Cooper MS, Stewart PM. Corticosteroid insufficiency in acutely ill patients. N Engl J Med 2003; 348: 727-734.

17 Rothwell PM, Udwadia ZF, Lawler PG. Cortisol response to corticotropin and survival in septic shock. Lancet 1991; 337: 582-583.

18 Gannon TA, Britt RC, Weireter LJ, Cole FJ, Collins JN, Britt LD. Adrenal insufficiency in the critically ill trauma population. Am Surg 2006; 72: 373-376.

19 Bernard F, Matta BF. Adrenal insufficiency after brain injury. Intensive Care Med 2006; 32: 793.

20 Kolbe J, Wells A, Ram FS. Inhaled steroids for bronchiectasis. Cochrane Database Syst Rev 2000: 2; CD000996.

21 Jain NK, Gupta KN, Sharma TN, Garg VK, Agnihotri SP. Airway obstruction in bronchiectasis and its reversibility a study of 38 patients. Indian J Chest Dis Allied Sci 1992; 34: 7-10.

22 Ip M, Lam WK, So SY, Liong E, Chan CY, Tse KM. Analysis of factors associated with bronchial hyperreactivity to methacholine in bronchiectasis. Lung 1991; 169: 43-51.

23 Chikanza IC, Petrou P, Kingsley G, Chrousos G, Panayi GS. Defective hypothalamic response to immune and inflammatory stimuli in patients with rheumatoid arthritis. Arthritis Rheum 1992; 35: 1281-1288.

24 Gaillard RC, Turnill D, Sappino P, Muller AF. Tumour necrosis factor- $\alpha$ inhibits the hormonal response of the pituitary gland to hypothalamic releasing factors. Endocrinology 1990; 127: 101-106.

25 Jaattela M, Ilvesmaki V, Voutilainen $\mathrm{R}$, Stenman UH, Saksela E. Tumour necrosis factor as a potent inhibitor of adrenocorticotropin-induced cortisol production and steroidogenic P450 enzyme gene expression in cultured human foetal adrenal cells. Endocrinology 1991; 128: 623-629.

26 Calogero AE, Sternberg EM, Bagdy G, et al. Neurotransmitter-induced hypothalamic-pituitary-adrenal axis responsiveness is defective in inflammatory disease-susceptible Lewis rats: in vivo and in vitro studies suggesting globally defective hypothalamic secretion of corticotropinreleasing hormone. Neuroendocrinology 1992; 55: 600-608.

27 Agwu JC, Spoudeas H, Hindmarsh PC, Pringle PJ, Brook CG. Tests of adrenal insufficiency. Arch Dis Child 1999; 80: 330-333.

28 Kaliner MA. Pharmacologic characteristics and adrenal suppression with newer inhaled corticosteroids: a comparison of ciclesonide and fluticasone propionate. Clin Ther 2006; 28: 319-331. 